\title{
DISCURSO PRONUNCIADO POR EL PRESIDENTE DEL COLEGIO MÉDICO DE CHILE, DR. PABLO RODRÍGUEZ, CON MOTIVO DE LA FIRMA DEL PROYECTO DE LEY SOBRE RESTITUCIÓN DE LA TUICIÓN ÉTICA PARA LOS COLEGIOS PROFESIONALES (http://www.colegiomedico.cl/Portals/O/htmls/boletines/boletin_especial018.html)
}

Excelentísima Presidenta Dra. Michelle Bachelet Jeria, señores Ministros y autoridades de Gobierno, señores Parlamentarios, representantes de los Colegios Profesionales:

Este es un día histórico para los profesionales de Chile. Hoy, después de 27 años, los Colegios Profesionales ven con esperanza este momento en que se firma el proyecto de ley que la Presidenta de la República enviará al Congreso para su tramitación legislativa y que permitirá recuperar la tuición ética a los Colegios Profesionales. A nombre de todos los profesionales de Chile, quiero agradecerle, Presidenta, el compromiso asumido por usted el pasado 21 de mayo y que hoy hace realidad. Muchas gracias, Presidenta, gracias por escuchar nuestros planteamientos y dar inicio al trámite legislativo. Queremos que esta ley se haga realidad durante su gobierno. Por ello hacemos un llamado a todos los sectores políticos y a los parlamentarios sin excepción a que la tramitación de este proyecto nos permita cumplir con este objetivo. La importancia que tiene este proyecto es que permitirá a los Colegios Profesionales tener un efectivo control ético sobre el ejercicio profesional de sus asociados, también permitirá velar por el prestigio de las profesiones y asegurar que las personas puedan recurrir a instancias jurisdiccionales apropiadas cuando consideren que su derecho a una buena atención ha sido vulnerado, hecho que consideramos de la mayor importancia, ya que será un eficiente mecanismo de control social. Hoy que la ciudadanía nos exige cada vez mayores grados de transparencia y horizontalidad en las relaciones, recuperar la tuición ética ayudará a fortalecer estos mecanismos de convivencia. En el año 1981 los Colegios Profesionales recibieron la peor estocada de su exis- tencia, cuando se les transformó en Asociaciones Gremiales, sin control ético sobre sus asociados, dejando a la sociedad más desprotegida ante una eventual falta al comportamiento ético de un determinado profesional. Hoy no queremos mirar al pasado, queremos construir el futuro. Por ello estamos trabajando desde el año 2005, cuando se aprobó una serie de enmiendas a la Constitución Política del Estado de 1980, en que en el artículo 19, $\mathrm{N}^{\circ}$ 16 se señala: "Los Colegios Profesionales constituidos en conformidad a la ley y que digan relación a tales profesiones, estarán facultados para conocer de las reclamaciones que se interpongan sobre la conducta ética de sus miembros. Contra sus resoluciones podrá apelarse ante la Corte de Apelaciones respectiva. Los profesionales no asociados serán juzgados por los Tribunales especiales establecidos en la ley". Tras la aprobación de esta enmienda constitucional, se constituyó una Mesa de Trabajo entre los Colegios Profesionales y el Ministerio Secretaría General de la Presidencia para dar forma a lo que hoy es este proyecto de ley. Básicamente, se establece un Registro Nacional de Profesionales, lo que permitirá a cualquier individuo conocer si una persona es arquitecto, médico, periodista u otro profesional. Del mismo modo, este cuerpo legal establece distintas sanciones por infracciones a la ética profesional. Consigna que los Colegios Profesionales dejan de ser Asociaciones Gremiales y se convierten en personas jurídicas de derecho público, lo cual es concordante con las funciones jurisdiccionales que se les otorgan. Además el proyecto establece, entre otras materias de interés, códigos éticos o deontológicos para cada profesión, señalando un procedimiento para la elaboración de estos, los que serán aprobados a través de un 
decreto supremo. Quiero finalizar, suscribiendo formalmente a nombre de los Colegios Profesionales nuestro compromiso de avanzar en el correcto ejer- cicio de nuestras profesiones.

Dr. Pablo Rodríguez.

Santiago, 10 de Junio de 2009.

\section{Crónica}

\section{INVITACIÓN AL XXXII CONGRESO CHILENO DE OBSTETRICIA Y GINECOLOGÍA: UN TRABAJO EN EQUIPO}

Hoy la medicina y particularmente nuestra especialidad, está sujeta a diversos cambios que nos ponen como principal desafío fortalecer los trabajos en equipo. Vemos cada día como el contacto electrónico reemplaza al contacto directo en múltiples áreas, incluyendo especialmente la difusión del conocimiento. No obstante, creemos que la difusión presencial y la interacción directa con los docentes, mantiene un rol trascendente para el saber de nuestra especialidad. Es por esto que la realización del Congreso Chileno de Obstetricia y Ginecología posee una especial relevancia, como un foro periódico de nuestra especialidad, para la puesta al día de conocimientos, así como la posibilidad de presentar nuestras experiencias clínicas a través de Contribuciones.

Bajo ese escenario, el actual Directorio de la Sociedad Chilena de Obstetricia y Ginecología, tiene dentro de sus metas incorporar a través de acciones concretas a las Sociedades Relacionadas, así como también a instituciones nacionales e internacionales ligadas a la especialidad.

Dentro de este propósito, en nuestro próximo XXXII Congreso Chileno de Obstetricia y Ginecología, a realizarse los días 22, 23 y 24 de noviembre en Viña del Mar, hemos hecho un esfuerzo conjunto entre el Centro de Diagnóstico e Investigaciones Perinatales y Ginecológicas de la Universidad Ca- tólica (CEDIP UC) y la Sociedad Chilena de Fertilidad, organizar en forma conjunta nuestra actividad científica bianual.

A este trabajo en equipo, también se sumaron la Sociedad Chilena de Climaterio (SOCHICLIM), la Sociedad Chilena de Ginecología Infantil y de la Adolescencia (SOGIA), The International Society for the Developmental Origins of Health and Disease (DOHaD) y el American College of Obstetricians and Gynecologists (ACOG), quienes estarán presentes a través de módulos y cursos.

La unión de todas estas entidades, nos permitirán contar con los más altos expositores nacionales e internacionales en los diversos campos de la ginecología y obstetricia. Será una excelente oportunidad para fortalecer nuestros conocimientos, mediante esta actividad de capacitación continúa y el éxito, una prueba clara de nuestra capacidad de organización.

Invitamos a médicos socios(as) y no socios(as) que ejercen la especialidad a lo largo de todo Chile, a participar activamente en esta reunión, que sin lugar a dudas contribuirá a perfeccionar nuestros conocimientos y capacitarnos para una mejor atención en la salud integral de la mujer.

Un muy cordial saludo,

Dr. Eugenio Suárez Pacheco. Presidente SOCHOG. 